\title{
ECOTOXICOLOGISTS MUST FACILITATE THE SETTING OF STANDARDS FOR SAFEGUARDING AQUATIC LIFE
}

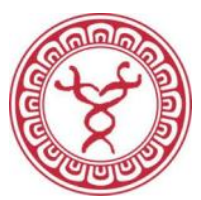

Wijesinghe M. R.

Department of Zoology and Environment Sciences, University of Colombo, Colombo 03.

\begin{abstract}
Intensified agriculture and accelerated development have resulted in large amounts of toxic chemicals entering our natural water bodies, imposing health risks to aquatic fauna. Considering the toxin levels at which ill effects are induced, the existing national guidelines for the release of effluents are seen to be inadequate for ensuring the safety of biota inhabiting these aquatic systems. The volume of research work on various aspects of ecotoxicology in Sri Lanka has increased in the recent past. A large majority of studies have focused on assessing the toxic effects of heavy metals - from among the wide range of toxicants - on selected aquatic and soil biota. Locally, many of the studies have used fish and amphibians for bioassays, while a few have investigated toxicity to earthworms and freshwater prawns. The frequently used endpoints of toxicity are the Lethal Concentrations (LC50 values). Other studies have evaluated the Effective Concentration (EC 50), Low effect concentration (LOEC) and No effect concentration (NOEC) considering sub-lethal impacts such as retardation in growth and development, occurrence of physical abnormalities, and histological, haematological and genetic aberrations. While many of the investigations so far have focused on selected species, ramifications at the community and ecosystem levels have not been assessed and still remain mere predictions. This article presents an overview of recent ecotoxicological research carried out in Sri Lanka on the effects of aquatic and soil toxicants on fauna. The scope of the published work has been outlined and the gaps in research identified. The article also touches upon directions for future ecotoxicological research in Sri Lanka.
\end{abstract}

Keywords: Ecotoxicology, bioassay, toxicity

*Corresponding author: E-mail: mayuri@sci.cmb.ac.lk

Received date: 27/04/2018, Accepted date: 08/05/2018

https://orcid.org/0000-0002-3402-951X

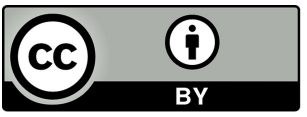

This is an open-access article distributed under the terms of the Creative Commons Attribution 4.0 International License which permits unrestricted use, distribution and reproduction in any medium provided the original author and source are credited. 
One of the important adverse effects of intensified agriculture and accelerated industrial development is the release of toxic waste which directly or indirectly enters water sources making them hazardous environments for the inhabitant organisms. Sri Lanka has myriad rivers, streams, estuaries and lagoons which deliver many goods and services essential for human life, whilst supporting a rich complement of endemic and other native species. To safeguard the potential of such natural ecosystems it is necessary that they be kept safe from toxicants.

The Central Environmental Authority (CEA) of Sri Lanka, a leading governmental body endowed with the mandate of safeguarding the environment, has recommended safety limits for effluent discharge. These guidelines specify a single maximum value for a given pollutant present in the industrial effluents discharged into surface water, assuming eight times dilution in the receiving waters. However, even assuming this degree of dilution, the toxicants in natural water bodies are often seen to exceed the safety limits. Let us take chromium as an example. The highest tolerance limit for the discharge of total chromium into inland surface waters is specified as $0.50 \mathrm{mg} / \mathrm{L}$, which, with eight times dilution in the receiving water, is expected to go down to 0.0625 $\mathrm{mg} / / \mathrm{L}$ (GOSL, 2008); whereas, ongoing research in over 90 sites in 19 water bodies across Colombo and greater Colombo has shown that, in approximately $15 \%$ of the sites, total $\mathrm{Cr}$ levels are above $0.07 \mathrm{mg} / \mathrm{L}$ (Pers. Comm.), which exceeds the allowed limit. Taking the more toxic state of chromium, i.e. hexavalent chromium (Cr VI), the allowed limit for discharge is $0.10 \mathrm{mg} / \mathrm{L}$ and it is expected to reduce to $0.0125 \mathrm{mg} / \mathrm{L}$ in the water body. Studies here and elsewhere have demonstrated that some zooplankton and marine invertebrates may suffer increased mortality and reduced reproduction at $0.01 \mathrm{mg} / \mathrm{L}$ with prolonged exposure to $\mathrm{Cr}$ (VI) (EPA, 1980; Oshida et. al., 1981). Not surprisingly, the Canadian Water Quality Guidelines are set at very low levels - the acceptable limit for safeguarding both freshwater and marine life is 0.0089 $\mathrm{mg} / \mathrm{L}$ for $\mathrm{Cr}(\mathrm{III})$ and $0.001 \mathrm{mg} / \mathrm{L}$ for $\mathrm{Cr}$ (VI) (Marine, 1999).

CEA Sri Lanka has also set provisional guidelines (Pers. Comm.) for the presence of toxicants in water, considering different end user categories such as drinking, irrigation, fish and other aquatic life, and recreation. For fish and other aquatic life, $0.02 \mathrm{mg} / \mathrm{L}$ of $\mathrm{Cr}$ has been given as the safety limit, while no limit is specified for $\mathrm{Cr}$ (VI). In Sri Lanka, no recent assessments have been made on the levels of $\mathrm{Cr}$ (VI) in surface water, presumably owing to the laborious and time-consuming methodology needed, and the outcome being of doubtful accuracy as reported by Sperling et al. (1992). Some studies done elsewhere have found that as much as $75-85 \%$ of total $\mathrm{Cr}$ in surface water constitutes $\mathrm{Cr}$ (VI) if the water has a neutral $\mathrm{pH}$ (Beaubein et al., 1994). Probably for this reason the Environment Protection Agency USA (EPA) (1980), in recommending safety levels, has adopted the precaution of considering that the total $\mathrm{Cr}$ in water comprises of $\mathrm{Cr}$ (VI), to afford maximum protection to aquatic life. These facts emphasize the need for stringent monitoring of effluents before permitting discharge into natural 
systems, and for adopting rigorous, science-based and comprehensive approaches for setting safety standards to preserve all forms of aquatic fauna. This is an area where ecotoxicologists could make a significant contribution.

The lately recognized discipline of ecotoxicology goes beyond the scope of conventional toxicology. The focus of research extends from purely toxicological assessments directed towards predicting adverse impacts of environmental contaminants on human life to a more holistic approach that attempts to predict ramifications at community and ecosystem levels. Consequently, over the past two decades, ecotoxicologists have been engaged in conducting bioassays using different faunal taxa. Much of the published work is based on empirical exposure trials, while some studies have made inferences regarding toxicity, based on field observations. This article presents an overview of recent ecotoxicological research carried out in Sri Lanka on the effects of aquatic and soil toxicants on fauna, outlining the scope of the published work, identifying gaps, and indicating directions for future research.

\section{Tested toxicants}

Many harmful substances plague our waterbodies, but not all of these have received adequate attention by local ecotoxicologists. A large majority of the studies in Sri Lanka have focused on examining the impacts of heavy metals, most likely because their presence in the environment has been suspected to have adverse effects on human health. Among the tested heavy metals are highly toxic metals such as $\mathrm{Cr}, \mathrm{Cd}$ and $\mathrm{Pb}$, and the moderately toxic $\mathrm{Cu}, \mathrm{Zn}$, and As. A notable omission here is $\mathrm{Hg}$ which has incidentally been recorded, at what are considered to be undesirable levels, in fish and shellfish from the Negombo lagoon (Sivanantha et al., 2016). Agrochemicals, both fertilizers and pesticides, have also been assessed in moderation. Some of the substances tested in toxicity trials are the pesticides bifenthrin, diazinon, chlorpyrifos, dimethoate, carbofuran, carbosulfan, carbendazin and mancozeb; and the herbicides glyphosate, propanil and paraquat. Although plant nutrients occur naturally in water bodies, high levels of these substances have been shown to induce adverse impacts on aquatic life. Nutrient enrichment due to the excessive use of fertilizers is commonly observed in natural water bodies. Nevertheless, the effects of exposure to nitrate and phosphate have been only examined at a preliminary level, using amphibians and fish.

\section{Taxa used for bioassays}

Over the years toxicology has been associated with mammalian models because of the direct relevance of the predicted impacts to human life. Latterly, however, with the realization that toxic substances have the capacity to accumulate and magnify, inducing toxic effects at different trophic levels, other organisms which are integral components of ecosystems were also used as subjects for bioassays. Elsewhere in the world, ecotoxicological research on amphibians and reptiles lagged behind that on other vertebrates such as fishes, birds, and mammals. In Sri Lanka, published scientific information shows that fish and 
amphibians have been more frequently used than the other taxa. The selection of taxa may have been guided by (a) the importance of species used as food resources (fishes) or (b) the recognition of species as sentinels of potential environmental pollution (amphibians). Virtually no studies have been done in Sri Lanka on the effects of pollutants on birds and reptiles, while studies on mammals are restricted to those with laboratory rats and mice. Among the anurans used are the native species Euphlyctis hexadactylus (Indian green frog), Polypedatus cruciger (Hourglass frog) and Duttaphrynus melanostictus (Common house toad). In the case of fish, most of the trials were performed on the exotic species Cyprinus carpio (carp), Oreochromis mossambicus (Mozambique tilapia), 0 . nilotica (Nile tilapia) and Poecilia reticulta (guppy), while a few have focused on native species e.g. Labeo dussumieri (Malabar labeo). Among the invertebrates used are some earthworms - Eisenia andrei, Eudrilus eugeniae. (Redworm) and Perionyx excavatus (Composting worm); freshwater crustaceans- Macrobrachium rosenbergii (Giant freshwater prawn) and Caridina nilotica; and the copepod Phyllodioptomus annae. A few studies have also been conducted on the cladocerans Daphnia and Moina (Pers. Comm.).

\section{Endpoints of toxicity}

Under field conditions, exposure concentrations, routes of entry, and exposure periods and regimes may vary considerably from one xenobiotc to another and from site to site, eliciting a diversity of toxic effects in the exposed organisms. Acute exposure trials bring out the potential of a contaminant to induce impacts if organisms are exposed to high doses over a short time period (generally 48 hrs [2 day] to 96 hrs [4 day]). Chronic exposure trials, on the other hand, measure effects that appear when exposed to low doses over a longer duration. The end points used to assess toxicity are spread over a wide spectrum, from lethality to a range of sublethal impacts. The most commonly used expression of the lethal potential of a toxicant is the LC50 - the concentration of the toxicant that kills $50 \%$ of the test population over a specified period. The calculation of LC50 is based on a doseresponse relationship obtained over a spectrum of exposure concentrations. One of the draw-backs of focusing on assessing LC50 values is the necessity to use high exposure levels which are most often not environmentally relevant. Many of the exposure trials have been designed in accordance with standard guidelines such as the OECD, with adequate replicates. Some of the reported LC50 values are given in Table 1.

Many of the native species in natural ecosystems are already threatened due to habitat alteration or loss, and selective extraction; pollution is an additional factor. Sub-lethal impacts in the long run lead to reduced replenishment and consequent population decline due to lowered fitness through reduced feeding and growth, reproductive retardation, delays in metamorphosis, impairment of behavior and lethargy, and occurrence of deformities. It is obvious then that assessing mortality alone would be inadequate in order to ensure the wellbeing of biota. Therefore, more recent studies elsewhere have resorted to assessing overall toxicity of a pollutant, using a combination of indicators - both 
Table 1. Published LC50 values for different faunal species that occur in natural ecosystems

\begin{tabular}{|c|c|c|c|c|}
\hline Endpoint & Species & Toxicant & Concentration & Reference \\
\hline \multirow[t]{5}{*}{ LC50 $48 \mathrm{hr}$} & Phyllodiaptomus annae & Glyphosate & $1.06 \mathrm{mgl}^{-1}$ & Deepananda et al. (2011) \\
\hline & Polypedates cruciger & Chlorpyrifos & $1.21 \mathrm{mgl}^{-1}$ & Jayawardena et al. (2010) \\
\hline & & Dimethoate & $8.40 \mathrm{mgl}^{-1}$ & Jayawardena et al. (2010) \\
\hline & & Glyphosate & $14.99 \mathrm{mgl}^{-1}$ & Jayawardena et al. (2010) \\
\hline & & Propanil & $2.21 \mathrm{mgl}^{-1}$ & Jayawardena et al. (2010) \\
\hline \multirow[t]{5}{*}{ LC50 14 day } & D. melanostictus & Chlorpyrifos & $3.0 \mathrm{mgl}^{-1}$ & Wijesinghe et al. (2011) \\
\hline & & Chlorpyrifos & $1.47 \mathrm{mgl}-1$ & Jayawardena et al. (2011) \\
\hline & & Dimethoate & $8.89 \mathrm{mgl}^{-1}$ & Jayawardena et al. (2011) \\
\hline & & Glyphosate & $45.94 \mathrm{mgl}^{-1}$ & Jayawardena et al. (2011) \\
\hline & & Propanil & $2.21 \mathrm{mgl}^{-1}$ & Jayawardena et al. (2011) \\
\hline LC50 14 day & D. melanostictus & Abate & $16.56 \mathrm{mgl}-1$ & Harischandra et al. (2011) \\
\hline LC50 96 hr & Caridina nilotica & Glyphosate & $60.97 \mathrm{mgl}^{-1}$ & Deepananda et al. (2011) \\
\hline $\mathrm{LC50}_{48 \mathrm{hr}}$ & Phyllodiaptomus annae & Glyphosate & $1.059 \mathrm{mgl}^{-1}$ & Deepananda et al. (2011) \\
\hline LC50 $96 \mathrm{hr}$ & Perionyx escavatus & Glyphosate & $32578 \mathrm{mgkg}^{-1}$ & De Silva \& Chandrasekara (2016) \\
\hline \multirow[t]{6}{*}{ LC50 28 day } & Perionyx escavatus & Chlorpyrifos & $122 \mathrm{mgkg}^{-1}$ & De Silva et al. (2010) \\
\hline & & Carbofuran & $9 \mathrm{mgkg}^{-1}$ & De Silva et al. (2010) \\
\hline & & Mancozeb & $541 \mathrm{mgkg}^{-1}$ & De Silva et al. (2010) \\
\hline & Eisenia andrei & Chlorpyrifos & $106 \mathrm{mgkg}^{-1}$ & De Silva et al. (2009) \\
\hline & & Carbofuran & $11.9 \mathrm{mgkg}^{-1}$ & De Silva et al. (2009) \\
\hline & & Carbendazim & $41.5 \mathrm{mgkg}^{-1}$ & De Silva et al. (2009) \\
\hline
\end{tabular}


lethal and sublethal. Also, there has been an attempt to assess Whole Effluent Toxicity (WET) which takes into account the overall impact of the effluent rather than focusing on the individual pollutants it contains. Here, toxicity is given as toxic units (TUs). These methods could prove to be more useful than individual toxicant assessments as effluents, often, are a mixture of toxicants bringing about combined effects on exposed animals.

Recently, scientists have become aware of the severe crisis that has befallen amphibian populations, including unexplained malformations and sudden extinctions. In many of these instances, contaminants have been identified as the probable cause, alerting ecotoxicologists worldwide. A few studies in Sri Lanka have assessed the potential of agrochemicals in inducing growth retardation, delays in development and metamorphosis, and malformations.

For amphibians, the reported deformities are mostly axial - abnormally curved thoracic spine (kyphosis), lateral deviation in the spine (scolosis), and inward curvature of a portion of the lumbar and cervical spine (lordosis) (e.g. Jayawardena et al., 2011) Some reported limb malformations are extra limbs (polymely), fewer limbs (amelia), incomplete limbs (ectromelia), and missing toes (ectrodactyly). A few studies have also reported feeding and swimming abnormalities in tadpoles exposed to pesticides and heavy metals (e.g. Ranatunge et al., 2012).

Other sublethal toxicity indicators are alterations in histology, haematology and genotoxicity. Histopathological studies on toxicant exposure have generally examined structural aberrations in the gills, liver and kidneys, organs which are critical in terms of toxicant exposure, breakdown or excretion. Some of the documented effects in young stages and adults of fish, amphibians and shrimps are structural distortions, clubbing and fusion of gill lamellae, necrosis, ulceration, oedema and degeneration of tissues. (e.g. Thenuwara et al., 2014; Bandara et al., 2012). Blood profiles are reported to be good indicators of the health status of species (Aleksandar et. al. 2005). Several haematological alterations such as changes in the counts of erythrocytes and leucocytes, and differential cell counts, PCV, Hb, MCV and $\mathrm{MCH}$, have been found to be induced by exposure to heavy metals. Bone marrow cell counts and spleenocyte counts have also been used as innate immune responses that indicate pollution stress. The effects on physiological functions have been assessed through changes in liver enzymes. The dose-dependency of these impacts has made it possible for some parameters to be used as biomarkers to signal threats of water pollution. Many of these studies are limited to one or two species of fish or amphibians. Only a handful of studies have focused on genotoxic effects of environmental pollutants in Sri Lanka. Published information reveals that nuclear fragmentation and DNA damage are induced in amphibians, fish and earthworms through exposure to heavy metals. For sublethal impacts, the commonly used measures are EC 50 (Effective concentration which induces impacts in $50 \%$ of the tested population), LOEC (Low effect concentration), and NOEC (No effect concentration). The sensitivity of an organism is age 
dependent. A few studies have shown that young stages are more susceptible to pollutants than the adults. It must be noted that many of the sub-lethal impacts generally occur as a result of continual exposure to low levels of pollutants. Under field conditions, after initial exposure, if there is dilution of pollutants, organisms may have a chance to recover. Therefore some impacts may not often be evident during field observations.

\section{Knowledge gaps and Future directions}

Accelerated discharge of effluents into the environment and the increased accumulation of pollutants have fueled the interests of ecotoxicologists. As expected, there has been an upsurge in the number of studies in the recent past that have investigated toxic impacts on biota. Ideally, their findings should provide a basis for setting guidelines on the maximum permissible levels of each toxicant in effluents in order to ensure the long-term survival of species in their natural habitats. However, there is no systematic data base which records the available information which could in turn inform policy makers. Furthermore, some important information is still lacking, necessitating prioritization of the areas in which research should be focused.

Evaluating toxic impacts under field conditions is problematic. The variability of pollutant levels, the presence of a wide range of pollutants inducing synergistic effects, and changes in ambient conditions such as acidity of the water and organic matter loads are factors that influence the nature and magnitude of the toxic effects. Furthermore, organisms generally evade polluted areas, and this ability to move from one location to another has prevented a direct linkage between the observed toxic effects and pollutant levels at a given site. Such impracticalities have motivated scientists to rely on empirical trials to ascertain the toxic potential of a particular environmental contaminant. However, it is becoming increasingly clear that extrapolating laboratory findings to field scenarios may not be realistic, and that for this reason the empirical approach alone may not be sufficient. Thus, as much as laboratory trials are needed, where possible, they should be substantiated using field based observations. A handful of studies in Sri Lanka have assessed how well endpoints recorded in organisms under laboratory conditions match those observed in organisms from polluted water bodies. Comparisons have also been done between organisms from polluted and unpolluted sites. This line of investigation must be strengthened in the future. Exposure trials could also be made more relevant by using locally applied pollutants (e.g. pesticides and fertilizers) and the low exposure levels generally observed in the field.

Many ecotoxicological questions remain to be solved while new ones have emerged. For instance, effects of nanomaterials on organisms have not been extensively investigated. Sub-lethal impacts of some of the toxic heavy metals such as $\mathrm{Hg}$ and As on native species are poorly understood. Collective effects should gain more importance because in reality organisms are exposed to a cocktail of pollutants. Abiotic factors such as temperature, acidity, and the amount of organic content in water bodies would alter the effects of a given toxicant. These aspects also need to be investigated. 
A few studies have investigated effects of pollutants under different temperature regimes while some have looked at the combined impacts of pesticides and biocides (e.g. parasites). Solar radiation has been shown to alter the toxic potential of some contaminants. Global warming is known to change the fate of chemicals in the environment through its effects on kinetics, which would in turn alter the magnitude of the toxic potential of contaminants. A few studies have linked exposures to accumulation in organisms, allowing inferences to be made with regard to the risks of exposure to field levels and the potential to biomagnify through food chains and webs. But, at present ramifications at the community and ecosystem levels remain mere predictions. These areas of study have not received much attention.

In terms of the taxa used for bioassays in Sri Lanka reptiles and birds among the vertebrates have not been used as study organisms, and hence even arbitrary predictions with regard to the potential effects of pollutants on them are difficult to make. Apart from the usual lethality and sub-lethal effects, preliminary work elsewhere has shown that some heavy metals affect colour development, which would in the long term be detrimental to many wild species. These provide interesting and novel avenues for research. More work is needed also to assess the effects of pollutants on important groups of aquatic reptiles and on macro benthos which are integral components of the food chain. Effects of pollutants have also been shown to be species-specific. Even among the better researched taxa, since widely occurring exotics such as Tilapia and Carp are preferentially used, likely due to the ease of collection and the increased applicability of research findings, there is a dire need to generate reliable toxicity data for native species. Although, worldwide, amphibians are used as ideal indicators of environmental health, this idea has recently been challenged. Analyses of over 20,000 toxicity studies worldwide have revealed that aquatic invertebrates (e.g. insects and brachiopods) may be better suited for monitoring contaminants than the amphibians, although, among the vertebrates, amphibians may be the most sensitive (Kaplan, 2009). This emphasizes the need to conduct comparative studies involving, at a minimum, one plankton species, a macrobenthic invertebrate, and an aquatic vertebrate, and to use the collective data to set safety guidelines. One significant limitation is that the available data are not organized into a data base, which would facilitate comparisons and the identification of data gaps, whilst avoiding replication. A maximum safety level of toxicants in effluents, that would have no adverse impact even over a long-term, may be recommended. If data are limited, it would be prudent to set interim guidelines using the available information, whilst urging ecotoxicologists to focus on the identified knowledge gaps.

There must be provision and flexibility at the policy level to alter decisions based on newly generated data. Safety limits should ideally target the protection of all forms of aquatic life, including the different life cycle stages. This would require the effluents to contain very low levels of the different toxicants. With more refined state-of-the-art treatment technologies being developed, and more 
precise quantitative measurements of pollutants being made possible, industrialists would be encouraged to lower the levels of pollutants discharged into water bodies and maintain the appropriately set ambient standards. Ecotoxicologists have a vital role to play in paving the way towards achieving this goal.

\section{References}

Aleksandar, I., Edhem, H., Svetlana, J., Dekić, R. (2005) Hematological Evaluation of welfare and health of fish. Praxis veterinaria 53: 191-202.

Bandara, M.G.D.K., Wijesinghe, M.R., Ratnasooriya, W.D., Priyani, A.A.H. (2012) Chlorpyrifos-induced histopathological alterations in Duttaphrynus melanostictus (Schneider 1799) tadpoles: Evidence from empirical trials. Journal of Tropical Forestry and Environment 2: 27-36.

Beaubien, S., Nriagu, J., Blowes, D., Lawso, G. (1994) Chromium Speciation and Distribution in the Great Lakes. Environmental Science and Technology 28: 730-736.

Deepananda, K.H.M.A., Gajamange, D., De Silva, W.A.J.P., Wegiriya, H.C.E. (2011) Acute toxicity of a glyphosate herbicide, Roundup $\AA$, to two freshwater crustaceans. Journal of the National Science Foundation Sri Lanka 39: 169173.

De Silva, S.M.S., Chandrasekara, W.U. (2016) Is the Widely Used Weedicide
Glyphosate that Bad? Toxic Effects of Glyphosate on the Earthworm Perionyx excavatus (Perrier, 1872). Proceedings of the International Forestry Symposium, Volume 21.

De Silva, P.M.C.S., Pathiratne, A., Van Gestel, C.A.M. (2009) Influence of temperature and soil type on the toxicity of three pesticides to Eisenia andrei. Chemosphere 76: 1410-1415.

De Silva, P.M.C.S., Pathiratne, A., Van Gestel, C.A.M. (2010) Toxicity of chlorpyrifos, carbofuran, mancozeb and their formulations to the tropical earthworm Perionyx excavates. Applied Soil Ecology 44: 56-60.

Environment Protection Agency (EPA) (1980) Ambient water quality criteria for chromium. U. S. Environment Protection Agency Report 440: 80-1035.

GOSL (2008) National Environment Act Gazette No. 1534/18 of The Democratic Socialist Republic of Sri Lanka.

Harischandra, H.K.S.P., Karunaratne, S.H.P.P., Rajakaruna, R.S. (2011) Effect of mosquito larvicide Abate $\AA$ on the developmental stages of the Asian common toad, Bufo melanostictus. Ceylon Journal of Science (Bio. Sci.) 40: 133-140.

Jayawardena, U.A., Rajakaruna, R.S., Navaratne, A.N., Amerasinghe, P.H. (2010) Toxicity of agrochemicals to common hourglass tree frog (Polypedates cruciger) in acute and chronic exposure. 
International Journal of Agricultural Biology 12: 641-648.

Jayawardena, U.A., Navaratne, A.N., Amerasinghe, P.H., Rajakaruna, R.S. (2011) Acute and chronic toxicity of four commonly used agricultural pesticides on the Asian common toad, Bufo melanostictus Schneider. Journal of the National Science Foundatation Sri Lanka 39: 267-276.

Kaplan, M. (2009) Amphibians rarely give earliest warning of pollution. Nature News Doi:10:10381048.

Marine, N. R. G. (1999) Canadian Water Quality Guidelines for the Protection of Aquatic Life. Canadian Environmental Quality Guidelines Canadian Council of Ministers of the Environment, Winniepeg 1-5.

Oshida, P.S., Word, L.S., Mearns, A J. (1981) Effects of hexavalent and trivalent chromium on the reproduction of Neanthes arenaceodentata.Marine Environmental Research 5: 41-49.

Ranatunge, R.A.A.R., Wijesinghe, M.R., Ratnasooriya, W.D., Dharmarathne, H.A.S.G., Wijesekera, R.D. (2012) Cadmium-induced toxicity on larvae of the Common Asian Toad Duttaphrynus melanostictus (Schneider, 1799): Evidence from empirical trials. Bulletin of Environmental Contamination and Toxicology 89(12): 143-146.
Sivanantha, N., Wijesinghe, M. R., Wijesekera R.D. (2016) Distribution of five toxic heavy metals in biotic and abiotic constituents of the Negombo lagoon. Sri Lankan Journal of Biology 1: 114.

Sperling, M., Xu, S., Welz B. (1992) Determination of chromium(III) and chromium(VI) in water using flow injection on-line preconcentration with selective adsorption on activated alumina and flame atomic absorption spectrometric detection. Analytical Chemistry 64: 3101 - 3108.

Thenuwara, T.T.K., Wijesinghe, M.R., de Silva, D.N., Wijesekara, R.D. (2014). Histopathological changes in post larvae of Macrobrachium rosenbergii following nitrate and phosphate exposure. Proceedings of the Thirty fourth Annual Sessions of the Institute of Biology, Sri Lanka.

Wijesinghe, M.R., Bandara M.G., Ratnasooriya W.D., Lakraj, G.P. (2011) Chlorpyrifos-induced toxicity in Duttaphrynus melanostictus (Schneider 1799) larvae. Archives of Environmental Contamination and Toxicology 60: 690696. 